\title{
Platinum particles deposited on synthetic boron-doped diamond surfaces. Application to methanol oxidation ${ }^{\text {s }}$
}

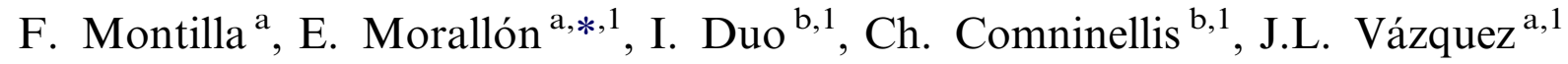 \\ ${ }^{a}$ Departamento de Química Física, Universidad de Alicante, Apartado 99, 03080 Alicante, Spain \\ ${ }^{\mathrm{b}}$ Faculty of Basic Science, Swiss Federal Institute of Technologie, CH-1015 Lausanne, Switzerland
}

Received 15 October 2002; received in revised form 12 December 2002; accepted 3 February 2003

\begin{abstract}
Two methods have been used for the deposition of Pt particles on synthetic boron-doped diamond (BDD) surfaces: chemical deposition and electrodeposition under potentiostatic conditions. However, electrodeposition leads much higher platinum dispersion than chemical deposition. The mechanism of nucleation and growing of the electrodeposited platinum was investigated by means of chronoamperometric studies in acid medium. The electrodeposition on diamond surfaces shows a mechanism of progressive nucleation as deduced from the chronoamperometric studies in acid medium. The stability of the deposited platinum is very low and the platinum particle are dissolved/detached by cycling. The modified BDD electrodes by deposition of platinum have been tested for the oxidation of methanol, showing that multi-step deposition results in higher values of surface and mass activities for methanol oxidation than one-step deposition process.
\end{abstract}

(C) 2003 Elsevier Ltd. All rights reserved.

Keywords: Diamond electrodes; Electrocatalysis; Platinum catalyst; Electrodeposition; Methanol oxidation

\section{Introduction}

The determination of the electrochemical properties of supported catalyst particles $\left(\mathrm{Pt}, \mathrm{Ru}, \mathrm{IrO}_{2}, \mathrm{RuO}_{2}\right.$ ) is of great interest for fundamental and technical applications. The main interest is related to the different and sometimes novel properties of supported catalysts compared with that of bulk materials.

Different supports have been used such as glassy carbon (GC), titanium and gold. However, these supports present some problems like low stability (in the case of $\mathrm{GC}$ ) or the formation of oxides ( $\mathrm{Ti}, \mathrm{Au}$ ) at high anodic potentials.

The recent achievements in the preparation of highly boron-doped diamond (BDD) on p-Si substrate (p-Si/

\footnotetext{
${ }^{25}$ From a lecture given at the 4th International Conference on "Electrocatalysis: From Theory to Industrial Applications", 22-25 September 2002, Como, Italy.

* Corresponding author. Tel.: +34-9-6590-9590; fax: +34-9-65903537.

E-mail address: morallon@ua.es (E. Morallón).

${ }^{1}$ ISE member.
}

BDD) can be an interesting approach to the above problems because this material can be used as support of the catalyst. The advantages of BDD as support of the catalyst are the following: (i) it does not form a macroscopic oxide layer on its surface when it is put in contact with an aqueous solution, (ii) it shows a high chemical and electrochemical stability, (iii) BDD has a very low background current and large electrochemical window $[1,2]$, and (v) the BDD electrode can also be heated in air up to $500{ }^{\circ} \mathrm{C}$ without undergoing a significant surface oxidation. However, BDD presents a very weak interaction with the catalyst and, therefore, low catalyst dispersion results. This fact favours the formation of 3D clusters towards layer by layer deposition.

The electrochemical behaviour of diamond thin films deposited on p-Silicon substrates (p-Si/BDD) has been studied for its use on electrochemical oxidation of organic wastes [3-5]. Several papers deal with the deposition of metallic particles (mercury, lead, lead dioxide, silver, ruthenium and platinum) on diamond supports [6-8]. The deposition and co-deposition of the platinum metal on diamond films have been the most 
studied systems due to their high interest in electrocatalysis [9-11]. Platinum deposits on carbonaceous support (graphite, GC, ceramic composites...) have received great attention due to their applicability to the fuel cell, being the methanol oxidation the preferred test reaction [12-16].

This work studies the preparation and the electrocatalytic behaviour of platinum particles deposited on $\mathrm{p}$ $\mathrm{Si} / \mathrm{BDD}$ substrate ( $\mathrm{p}-\mathrm{Si} / \mathrm{BDD} / \mathrm{Pt}$ electrodes). Two techniques have been used in the preparation of $\mathrm{p}-\mathrm{Si} / \mathrm{BDD} /$ Pt electrodes: the thermal decomposition and electrodeposition under potentiostatic conditions. Finally, the reaction of methanol oxidation in acid medium has been used as reaction test of the prepared $\mathrm{p}-\mathrm{Si} / \mathrm{BDD} / \mathrm{Pt}$ electrodes.

\section{Experimental}

The p-Si/BDD electrodes (which have been used as support for Pt catalyst) were provided and synthesized by the Swiss Center for Electronics and Microtechnology SA, Neuchâtel, Switzerland using the hot filament chemical vapour deposition technique (HF-CVD) on conducting p-Si. The obtained diamond film thickness was about $1 \mu \mathrm{m}$.

The as-prepared $\mathrm{p}$-Si/BDD support contains some graphitic phase $\left(\mathrm{sp}^{2}\right)$ and is hydrogen terminated inherent to its preparation technique. The presence of these functionalities on the BDD surface results to an increase in the background current, to a decrease in the electrochemical window and to a hydrophobic surface. Activation of the $\mathrm{p}-\mathrm{Si} / \mathrm{BDD}$ support by anodic polarization $\left(30 \mathrm{~min}\right.$ at $10 \mathrm{~mA} \mathrm{~cm}{ }^{-2}$ in $1 \mathrm{M} \mathrm{H}_{2} \mathrm{SO}_{4}$ at $25^{\circ} \mathrm{C}$ ) results in the elimination of most of $\mathrm{sp}^{2}$ and adsorbed hydrogen from the BDD surface. In fact the background current is dramatically reduced and the BDD surface became hydrophilic after this anodic pre-treatment. However, XPS measurements have shown that the O/ $\mathrm{C}$ ratio increases after this treatment. This indicates the formation of new functionalities $(\mathrm{C}-\mathrm{OH}, \mathrm{C}-\mathrm{O}, \mathrm{C}=\mathrm{O})$ on the BDD surface. It is worthwhile to mention at this stage that this treatment is essential in order to obtain reproducible electrochemical measurements [17].

After this pre-treatment the platinum was deposited by two methods:

a) Chemical deposition using the thermal decomposition technique: This method consists in the application of $5 \mu \mathrm{l}$ of a platinum precursor solution $(0.2-3 \mathrm{mM}$ $\mathrm{H}_{2} \mathrm{PtCl}_{6}$ in $i s o$-propanol) on the diamond surface (1 $\mathrm{cm}^{2}$ ), evaporation of the solvent at $60{ }^{\circ} \mathrm{C}$ during 5 min, and finally, thermal decomposition of the precursor by treatment in an oven at $350{ }^{\circ} \mathrm{C}$ during $1 \mathrm{~h}$. b) Electrochemical deposition of Pt under potentiostatic conditions: This method consists in the deposition of the platinum on the pre-treated $\mathrm{p}$-Si/BDD support under potentiostatic conditions from a $0.5 \mathrm{M}$ $\mathrm{H}_{2} \mathrm{SO}_{4}+2 \mathrm{mM} \mathrm{H}_{2} \mathrm{PtCl}_{6}$ solution.

All electrochemical measurements were carried out with an EG\&G Potentiostat/Galvanostat model 273 controlled by software ECHEM M270. Working electrode were $\mathrm{p}$-Si/BDD/Pt plates of $1 \mathrm{~cm}^{2}$. The current densities are calculated using this geometric area. The counter electrode was a platinum wire and the reference electrode was a $\mathrm{Hg} / \mathrm{Hg}_{2} \mathrm{SO}_{4}-\mathrm{K}_{2} \mathrm{SO}_{4}$ (saturated). All the potentials are referred to the reversible hydrogen electrode (RHE). All solutions were prepared with high purity water (Millipore, Milli-Q).

\section{Results and discussion}

\subsection{Characterization of $p$-SilBDD/Pt prepared by the thermal decomposition technique}

Fig. 1 shows the SEM images of platinum deposited on $\mathrm{p}$-Si/BDD by thermal decomposition with $15 \mathrm{nmol}$ $\mathrm{cm}^{-2}$ of Pt. This electrode shows irregular distribution of platinum clusters on the diamond surface (white spots in Fig. 1a). A micrograph obtained with a higher magnification (Fig. 1b) shows cluster of around $3 \mu \mathrm{m}$ long formed by agglomeration of platinum particles of around $0.2 \mu \mathrm{m}$ of diameter.

This agglomeration of the platinum particles is related to the inhomogeneity of the interfacial surface tension of the BDD support. In fact, the presence of different functionalities on the activated BDD can modify the local surface tension of the BDD surface and results in a non-uniform distribution of the platinum precursor during application of the precursor solution. Furthermore, sintering of the particles takes place during the thermal treatment.

The Si/BDD/Pt electrodes prepared by thermal decomposition show in the voltammogram (figure not shown) the characteristic peaks corresponding to oxide formation (anodic peak at $1.1 \mathrm{~V}$ ) and oxide reduction (cathodic peaks at $0.4-0.6 \mathrm{~V}$ ). However, the voltammogram does not show the peaks corresponding to hydrogen adsorption-desorption processes (between 0.05 and $0.3 \mathrm{~V}$ ). The shift to lower potentials of the adsorptiondesorption processes involved between 0.06 and $0.45 \mathrm{~V}$ and the decrease of the reversibility of the platinum oxide/platinum couple can be explained by the presence of residual chlorine on the platinum surfaces. In fact, chorine has been detected by XPS.

The stability of these electrodes has been tested by cycling between oxygen and hydrogen evolution reactions. After 500 cycles at $50 \mathrm{mV} \mathrm{s}^{-1}$ the obtained cyclic 


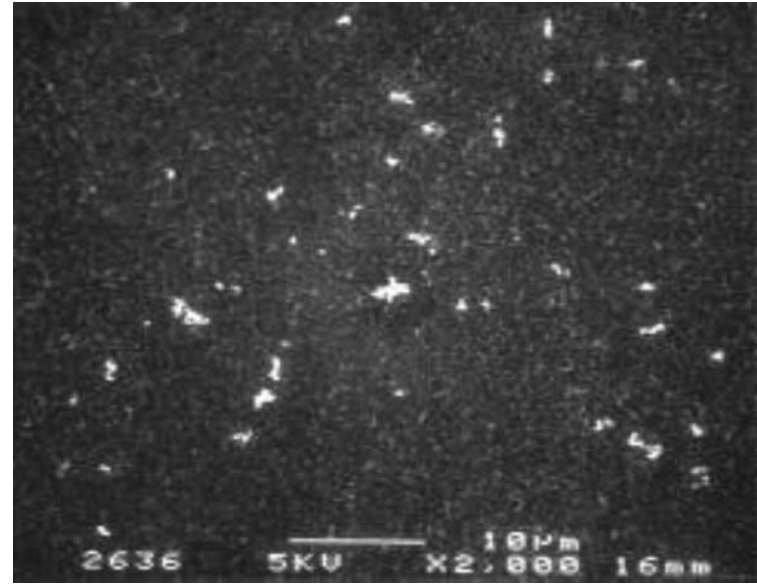

(a)

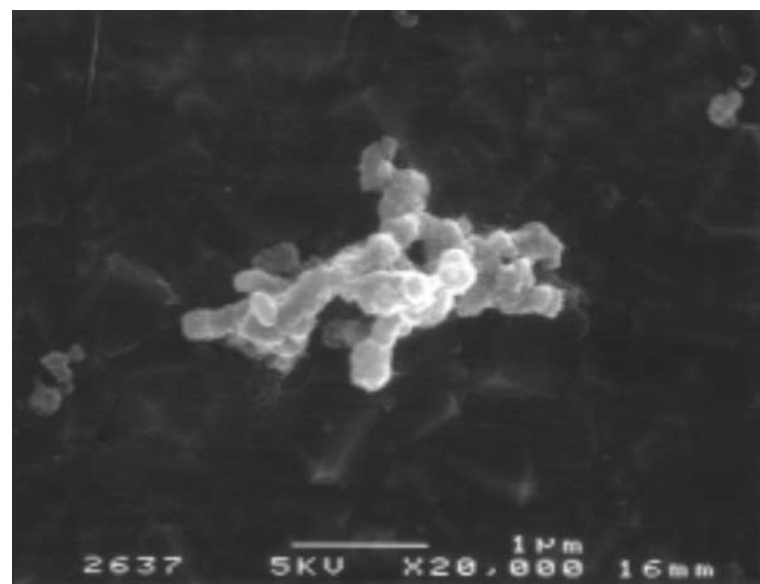

(b)

Fig. 1. SEM images of $\mathrm{p}-\mathrm{Si} / \mathrm{BDD} / \mathrm{Pt}$ electrode at two magnifications: (a) 2000 and (b) 20000 prepared by the thermal decomposition technique, Pt loading: $15 \mathrm{nmol} \mathrm{cm}{ }^{-2}$.

voltammogram (figure not included) does not show the characteristic peaks of the platinum oxide formation and reduction. Furthermore, the SEM images obtained after this treatment show the absence of platinum particles on the diamond surface. These facts indicate the dissolution/detachment of the platinum by the potential cycling.

\subsection{Preparation and characterization of $p-S i / B D D / P t$ by electrodeposition}

\subsubsection{Preparation of $p$-Si/BDD/Pt by electrodeposition}

Fig. 2 shows a cyclic voltammogram (first cycle) of a p-Si/BDD electrode in a $0.5 \mathrm{M} \mathrm{H}_{2} \mathrm{SO}_{4}+2 \mathrm{mM} \mathrm{H}_{2} \mathrm{PtCl}_{6}$ solution. In the forward scan towards negative potentials a reduction peak at $0.35 \mathrm{~V}$ appears, which corresponds to the reduction of $\mathrm{Pt}^{4+}$ to metallic $\mathrm{Pt}$ on the diamond surface. At potentials close to $0 \mathrm{~V}$, the hydrogen evolution reaction starts on the electrodeposited platinum.

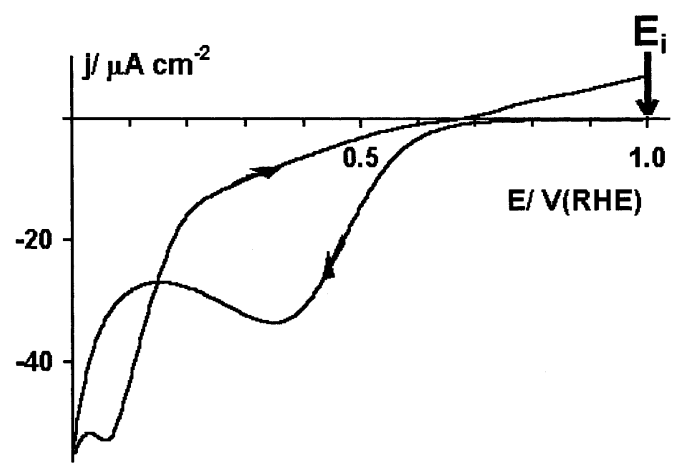

Fig. 2. Cyclic voltammogram (first scan) of $\mathrm{p}-\mathrm{Si} / \mathrm{BDD}$ in $0.5 \mathrm{M}$ $\mathrm{H}_{2} \mathrm{SO}_{4}+2 \mathrm{mM} \mathrm{H}_{2} \mathrm{PtCl}_{6}$. Initial potential $\left(E_{i}\right): 1.0 \mathrm{~V}$ per RHE, scan rate: $50 \mathrm{mV} \mathrm{s}^{-1}, T=25^{\circ} \mathrm{C}$.

The mechanism of the electrochemical deposition of platinum on diamond was studied by means of chronoamperometric experiments. Fig. 3 plots the current vs. time in a potentiostatic step experiment (from an initial potential of $1.0-0.1 \mathrm{~V}$ ). This plot is very similar to the theoretical potentiostatic current-time transient for electrochemical deposition [18]. Four well-defined time intervals can be identified and are marked in Fig. 3. At the beginning of the first time interval (zone I in Fig. 3), a sharp increase followed by a decay of the current appears that corresponds to the double-layer charging current and the initial nucleation process. In the second time interval (zone II in Fig. 3), the current increases due to the free growth of independent nuclei for deposition or to the formation of new nucleation sites without overlapping effects. In the third time interval (zone III in Fig. 3) two opposed effects occur: the growth of independent nuclei and nuclei overlap. The current increases in this zone reaching a maximum in which nuclei overlapping happens. After that, in the forth time interval, the current decreases due to the overlapping of the diffusion zones of different nuclei, and the coalescence of the growth centers (zone IV in Fig. 3). From this time ( $t_{\mathrm{m}}$ in Fig. 3$)$, the current decreases as a result of a decrease in the surface area of platinum particles and, then, it can be considered that a change in the hemispherical to linear mass transfer diffusion occurs as consequence of the increase in the particle size.

In the interval of free growing of nuclei (zone II) the transient current-time curves can be plotted to give linear $I^{1 / 2}$ vs. $t$ plots. This behaviour indicates a $3 \mathrm{D}$ nucleation process with hemispherical nucleus with diffusion control [18]. Based on this model Scharifker and Hills [19] developed a theoretical relationship for the determination of the nucleation mechanism between instantaneous or progressive nucleation. In the instantaneous nucleation mechanism all the nuclei are rapidly created and their number remain constant during the growth process. The other possible mechanism is the 


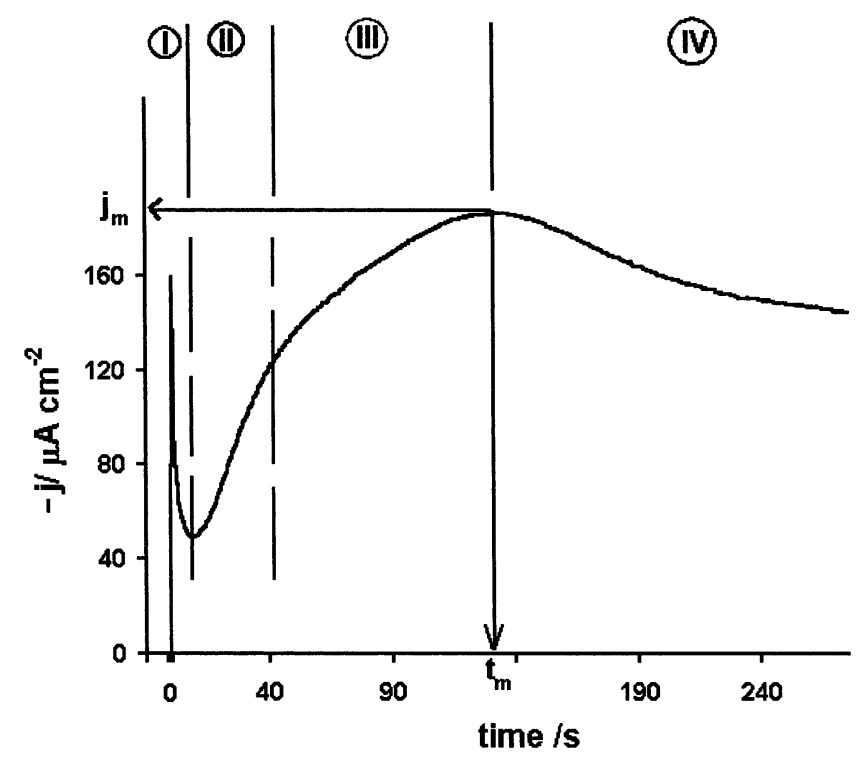

Fig. 3. Current vs. time transient plot obtained during the potentiostatic experiment (at $0.1 \mathrm{~V}$ ) of $\mathrm{p}-\mathrm{Si} / \mathrm{BDD}$ in a $0.5 \mathrm{M} \mathrm{H}_{2} \mathrm{SO}_{4}+2 \mathrm{mM}$ $\mathrm{H}_{2} \mathrm{PtCl}_{6}$ solution. Initial potential $1.0 \mathrm{~V}$. The different time intervals during deposition are marked (zones I-IV) and the maximum current density $\left(j_{\mathrm{m}}\right)$ and the corresponding maximum time $\left(t_{\mathrm{m}}\right)$ are reported (see text).

progressive nucleation where the nucleation rate is low and new nuclei are continuously forming during the whole deposition process. Fig. 4 shows the transient current-time plotted in reduced variables (curve a) together with the theoretical plots for both mechanisms (curves $\mathrm{b}$ and $\mathrm{c}$ for progressive nucleation and instantaneous nucleation, respectively). It can be observed that the experimental curve fits better to the progressive nucleation mechanism. This result is similar to those obtained by Gloagen et al. on the deposition of platinum on graphite [20].

Fig. 5 shows the SEM micrographs of $\mathrm{Si} / \mathrm{BDD} / \mathrm{Pt}$ electrodes prepared by a single potential step to $0.15 \mathrm{~V}$ during $480 \mathrm{~s}$. Since the mechanism of nucleation is

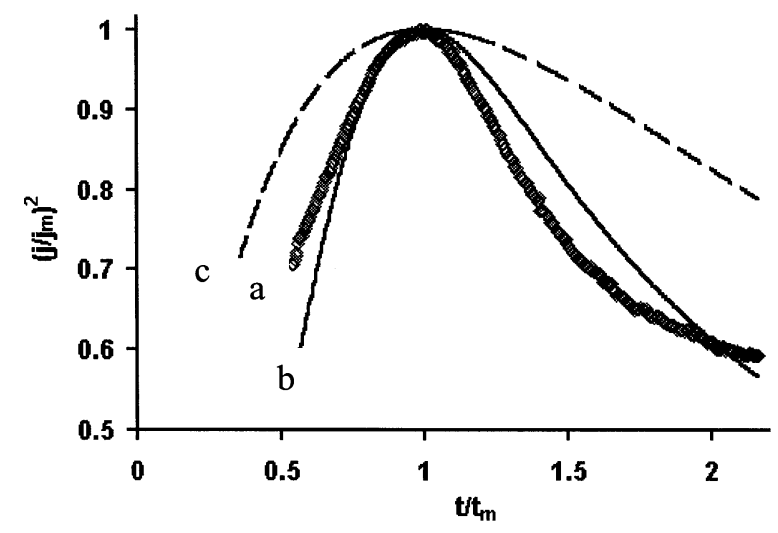

Fig. 4. Current-time transient response plotted in reduced variables $\left[\left(j / j_{\mathrm{m}}\right)^{2}\right.$ vs. $\left.t / t_{\mathrm{m}}\right]$. (a) Experimental values calculated. (b) Theoretical data for progressive nucleation [20]. (c) Theoretical data for instantaneous nucleation [20]. progressive it can be observed spherical platinum particles with different sizes ranging from 0.15 to 0.7 $\mu \mathrm{m}$. This is indicative that the nuclei are formed in different stages during the deposition process. It is worthwhile to mention that electrodes prepared by electrodeposition have a much better platinum dispersion than the electrodes prepared by the thermal decomposition technique.

In order to improve the dispersion of the platinum particles, the electrodeposition was performed by means of eight successive potentiostatic steps of $60 \mathrm{~s}$ (total time of deposition $480 \mathrm{~s}$ ) at $0.15 \mathrm{~V}$. Fig. 6 shows the SEM micrograph obtained in these conditions. The comparison of Fig. 6 with Fig. 5 (one step deposition for $480 \mathrm{~s}$ at $0.15 \mathrm{~V}$ ) shows that together with micrometer platinum particles, nanoparticles between 10 and $50 \mathrm{~nm}$ are also obtained in case of multi-step electrodeposition.

The electrochemical deposition of platinum on diamond electrodes has been also performed at very negative potential $(-0.58 \mathrm{~V}$ during $60 \mathrm{~s})$. At this potential there are two possible parallel reactions: (i)

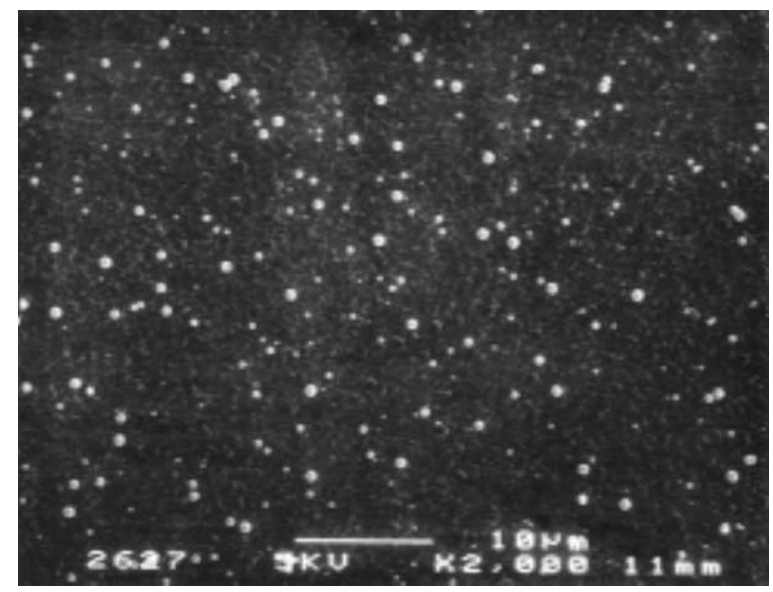

(a)

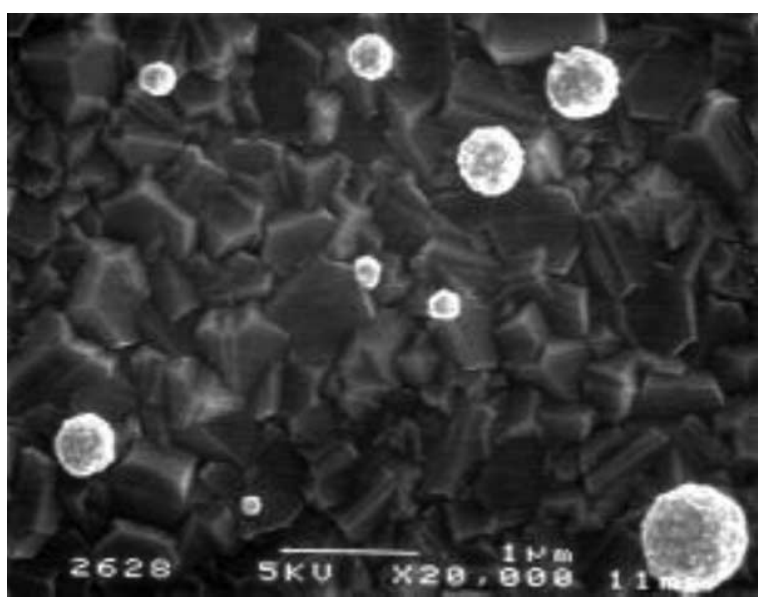

(b)

Fig. 5. SEM images at two magnifications of $\mathrm{p}-\mathrm{Si} / \mathrm{BDD} / \mathrm{Pt}$ electrode prepared by electrodeposition with a single potential step from 1.0 to $0.15 \mathrm{~V}$ during $480 \mathrm{~s}$ in $0.5 \mathrm{M} \mathrm{H}_{2} \mathrm{SO}_{4}+2 \mathrm{mM} \mathrm{H}_{2} \mathrm{PtCl}_{6}$ solution. 


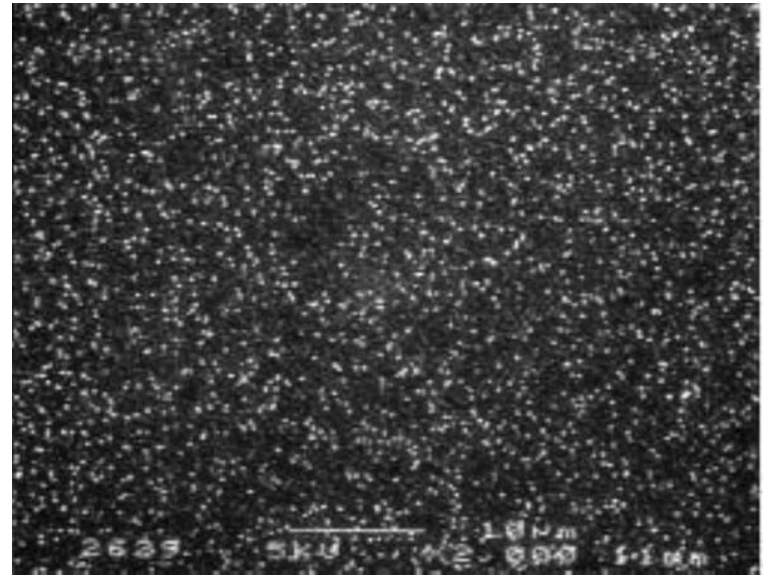

(a)

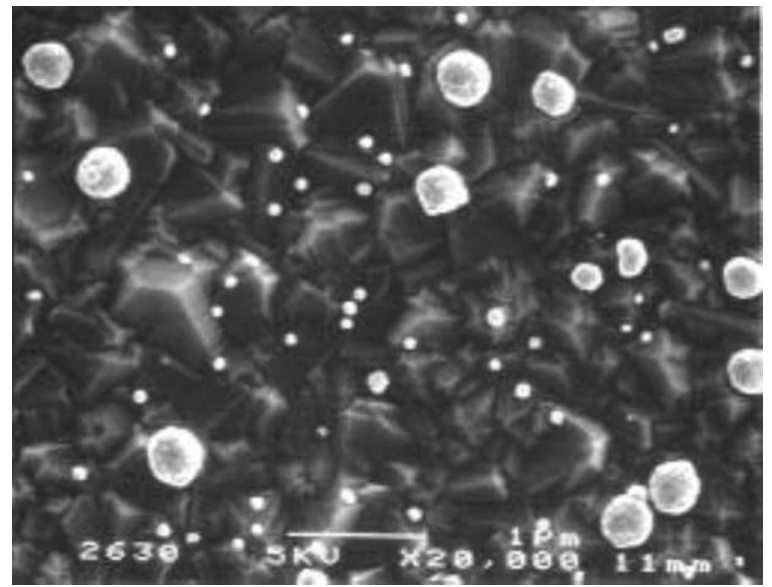

(b)

Fig. 6. SEM images at two magnifications of $\mathrm{p}-\mathrm{Si} / \mathrm{BDD} / \mathrm{Pt}$ electrode prepared by electrodeposition with an eight successive potential steps from 1.0 to $0.1 \mathrm{~V}$ during $60 \mathrm{~s}$ each, in $0.5 \mathrm{M} \mathrm{H}_{2} \mathrm{SO}_{4}+2 \mathrm{mM} \mathrm{H}_{2} \mathrm{PtCl}_{6}$ solution.

reduction of $\mathrm{Pt}^{4+}$ to metallic $\mathrm{Pt}$ on the diamond support, and (ii) hydrogen evolution on the electrodeposited platinum particles. The obtained platinum particles show irregular shapes and are not spherical. The dimensions of the particles are between 0.1 and $0.5 \mu \mathrm{m}$.

\subsubsection{Characterization of p-SilBDD/Pt prepared by electrodeposition}

The voltammograms obtained with Si/BDD/Pt electrodes prepared by electrodeposition are very similar to the one obtained with a polycrystalline platinum electrode. They show two well-defined zones corresponding to hydrogen and anion adsorption-desorption processes and platinum oxide formation-reduction processes.

Table 1 contains the characteristics of the platinum electrodeposited electrodes under different potentiostatic conditions. The amount of platinum electrodeposited has been calculated from the electrical charge of the chronoamperometric curves assuming that the only reaction that occurs during the electrodeposition is

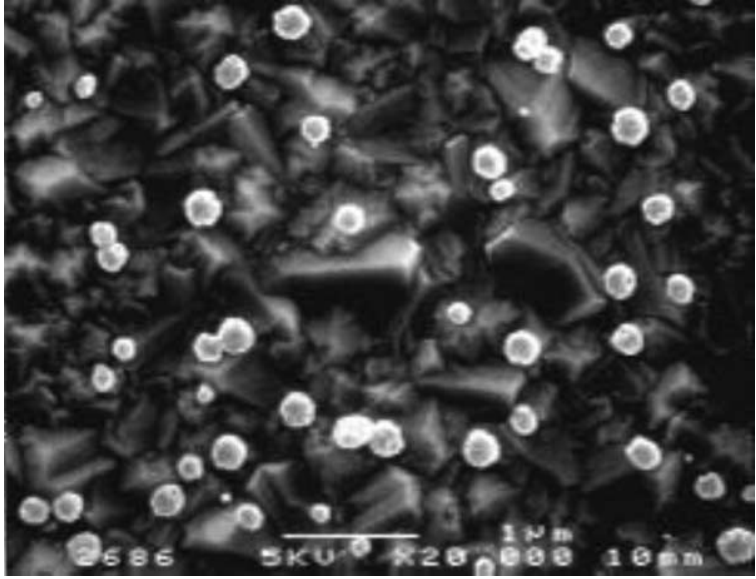

Fig. 7. SEM image of $\mathrm{p}-\mathrm{Si} / \mathrm{BDD} / \mathrm{Pt}$ electrode prepared by electrodeposition (electrode prepared as given in Fig. 8) after 1000 cyclic voltammograms in $0.5 \mathrm{M} \mathrm{H}_{2} \mathrm{SO}_{4}$.

$\mathrm{Pt}^{4+}+4 \mathrm{e}^{-} \rightarrow \mathrm{Pt}$. The specific surface area and the roughness factor (surface area by geometric one) of the $\mathrm{p}-\mathrm{Si} / \mathrm{BDD} / \mathrm{Pt}$ electrodes have been measured from the voltammetric charge involved in the peak corresponding to reduction of platinum oxides (considering $440 \mu \mathrm{C} \mathrm{cm}^{-2}$ for a bulk platinum electrode).

It can be observed in this Table 1 that the deposition mode (one-step or multi-step) strongly influences the specific surface area. In fact, multi-step deposition for the same time than one-step results in an increase in the specific electrode area by a factor of 3-7. This increase in the specific electrode area in multi-step deposition can be explained by the fact that multi-step deposition favours the formation of new nuclei.

\subsubsection{Stability of the $p-S i / B D D / P t$ electrodes prepared by electrodeposition}

The stability of the electrochemically deposited electrodes has been tested by cycling the potential (1000 cycles) between oxygen and hydrogen evolution reactions in a $0.5 \mathrm{M} \mathrm{H}_{2} \mathrm{SO}_{4}$ solution at a sweep rate of 50 $\mathrm{mV} \mathrm{s}^{-1}$. This treatment results in a dissolution/detach-

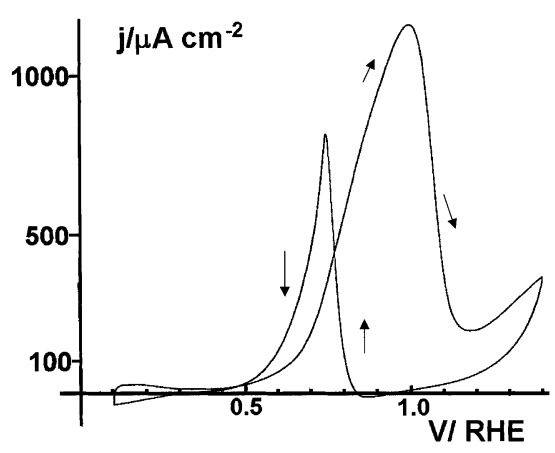

Fig. 8. Steady state cyclic voltammogram of $\mathrm{Si} / \mathrm{BDD} / \mathrm{Pt}$ electrode prepared by electrodeposition in $0.5 \mathrm{M} \mathrm{H}_{2} \mathrm{SO}_{4}+0.1 \mathrm{M}$ methanol solution, scan rate: $50 \mathrm{mV} \mathrm{s}^{-1}, T=25^{\circ} \mathrm{C}$. 
Table 1

Characteristics of $\mathrm{p}-\mathrm{Si} / \mathrm{BDD} / \mathrm{Pt}$ electrodes prepared by electrodeposition

\begin{tabular}{lllllll}
\hline $\begin{array}{l}\text { Sample } \\
\text { label }\end{array}$ & $\begin{array}{l}\text { Deposition poten- } \\
\text { tial (V) }\end{array}$ & $\begin{array}{l}\text { Number of deposition } \\
\text { pulses }\end{array}$ & $\begin{array}{l}\text { Deposited platinum } \\
\left(\mu \mathrm{g} \mathrm{cm}^{-2}\right)\end{array}$ & $\begin{array}{l}\text { Roughness } \\
\text { factor }\end{array}$ & $\begin{array}{l}\text { Specific surface area } \\
\left(\mathrm{m}^{2} \mathrm{~g}^{-1}\right)\end{array}$ & $\begin{array}{l}\text { Remaining Pt after 1000 } \\
\text { cycles }(\%)\end{array}$ \\
\hline e1 & 0.15 & 1 & 15.1 & 0.21 & 1.41 & Not measured \\
elb & 0.1 & 1 & 35.1 & 0.25 & 0.71 & 29 \\
e8 & 0.15 & 8 & 66.1 & 2.41 & 3.64 & 38 \\
e8b & 0.1 & 8 & 64.6 & 3.38 & 5.23 & 39 \\
eH & -0.58 & 1 & $<56.1^{\mathrm{a}}$ & 2.27 & $>4.04^{\mathrm{a}}$ & 38 \\
\hline
\end{tabular}

a Assuming 100\% current efficiency for Pt deposition.

ment of an important fraction of the deposited Pt. Table 1 shows that for almost all the investigated electrodes the amount of platinum presents on the electrode surface (estimated from the electrical charge in the cyclic voltammograms) after the potential cycling is reduced to about $35 \%$ with respect to the initial one.

Fig. 7 shows the SEM image of an electrode Si/BDD/ Pt (labelled e8 in Table 1) after cycling the potential (1000 cycles) between oxygen and hydrogen evolution reactions in a $0.5 \mathrm{M} \mathrm{H}_{2} \mathrm{SO}_{4}$ solution at a sweep rate of $50 \mathrm{mV} \mathrm{s}^{-1}$. The main difference observed with respect to the fresh electrode is that only particles of the micro scale dimension $(0.2-0.3 \mu \mathrm{m})$ are present. The voltammetric profile of this electrode is very similar to that obtained after the deposition process. However, the current has decreased considerably. This fact together with the decrease in the particle size observed by SEM indicates that the platinum is dissolved/detached upon potential cycling.

\subsubsection{Catalytic activity of the p-SilBDD/Pt electrodes prepared by electrodeposition}

Fig. 8 shows a typical cyclic voltammogram obtained during the tenth cycle for a $\mathrm{p}-\mathrm{Si} / \mathrm{BDD} / \mathrm{Pt}$ electrode in a $0.5 \mathrm{M} \mathrm{H}_{2} \mathrm{SO}_{4}+0.1 \mathrm{M}$ methanol solution. The activity of the electrode has been estimated from the anodic current peak obtained during the forward scan in the tenth cycle. Table 2 shows the oxidation potentials during the forward and reverse scan, the surface activity defined as the current related to the surface area of the platinum particles and the mass activity defined as the current related to the amount of deposited platinum. It can be observed in Table 2 that the multi-step deposition (in our case eight successive pulses) results in higher values of surface and mass activities for methanol oxidation in comparison to the one-step deposition process.

\section{Conclusion}

The BDD electrode is a suitable support for the characterization of electrocatalyst due to its high chemical and electrochemical stability, low background current, large electrochemical window and its high thermal stability. Specially, due to the low adsorption properties of $\mathrm{BDD}$, the binding energy between the platinum adatoms and the BDD support is much more weaker than the binding energy between the Pt adatoms themselves on the BDD surface. This can favour the 3D Pt crystal growth [18].

In this article, deposition of platinum particles has been carried out by the thermal decomposition technique and by electrodeposition.

Electrodeposition in a multi-step process has been found to be the most suitable method in order to obtain a well dispersed and more electrochemically stable catalyst than thermal decomposition. The electrodeposition of platinum follows a mechanism of progressive nucleation, which favours a higher dispersion of the platinum particles, increasing the amount of new nuclei for platinum deposition on the BDD support.

Cycling the potential between oxygen and hydrogen evolution reactions results in a specific dissolution/

Table 2

Oxidation of methanol on $\mathrm{p}-\mathrm{Si} / \mathrm{BDD} / \mathrm{Pt}$ prepared by electrodeposition

\begin{tabular}{|c|c|c|c|c|}
\hline \multirow[t]{2}{*}{ Sample label } & \multicolumn{2}{|c|}{ Oxidation potential $(\mathrm{V})$} & \multirow[t]{2}{*}{ Surface activity $\left(\mathrm{mA} \mathrm{cm}^{-2}\right)$} & \multirow[t]{2}{*}{ Mass activity $\left(\mathrm{A} \mathrm{g}^{-1}\right)$} \\
\hline & Forward scan & Reverse scan & & \\
\hline Smooth Pt & 0.81 & 0.72 & 873.6 & 0.0 \\
\hline elb & 0.85 & 0.71 & 496.5 & 3.51 \\
\hline $\mathrm{e} 8 \mathrm{~b}$ & 1.1 & 0.78 & 562.1 & 29.4 \\
\hline EH & 1 & 0.75 & 499.1 & $>20.2^{\mathrm{a}}$ \\
\hline
\end{tabular}

a Assuming 100\% current efficiency for Pt deposition. 
detachment of the deposited platinum particles on the BDD surface.

Finally, these modified BDD electrodes by deposition of platinum particles have been tested for the oxidation of methanol in acid medium. It has been found that multi-step deposition result in higher values of surface and mass activities for methanol oxidation in comparison to the one-step deposition process.

\section{Acknowledgements}

Financial support by the Ministerio de Ciencia y Tecnología and Feder project (MAT2001-1007) is gratefully acknowledged.

\section{References}

[1] Y.U. Pleskov, Russ. Chem. Rev. 68 (1999) 381.

[2] J.C. Angus, H.B. Miller, U. Landau, Y.E. Evstefeeva, B. Miller, N. Vinokur, New Diamond Front. Carbon Technol. 9 (1999) 175.

[3] F. Montilla, P.A. Michaud, E. Morallón, J.L. Vázquez, Ch. Comninellis, Electrochim. Acta 47 (2002) 3509.

[4] P.L. Hagans, P.M. Natishan, B.R. Stoner, W.E. O’Grady, J. Electrochem. Soc. 148 (2001) 7.E298.

[5] M. Panizza, P.A. Michaud, G. Cerisola, Ch. Comninellis, J. Electroanal. Chem. 507 (2001) 206.
[6] M. Awada, J.W. Strojek, G.M. Swain, J. Electrochem. Soc. 142 (1995) L42.

[7] N. Vinokur, B. Miller, Y. Avygail, R. Kalish, J. Electrochem. Soc. 146 (1999) 125.

[8] A.J. Saterlay, S.J. Wilkins, K.B. Holt, J.S. Foord, R.G. Compton, F. Marken, J. Electrochem. Soc. 148 (2001) E66.

[9] J. Wang, G.M. Swain, T. Tachibana, K. Kobashi, Electrochem. Solid State Lett. 3 (2000) 286.

[10] J. Wang, G.M. Swain, T. Tachibana, K. Kobashi, J. New Mat. Electrochem. Sys. 3 (2000) 75.

[11] K. Honda, M. Yoshimura, T.N. Rao, D.A. Tryk, A. Fujishima, K. Yasui, Y. Sakamoto, K. Nishio, H. Masuda, J. Electroanal. Chem. 514 (2001) 35.

[12] G. Meli, J.M. Leger, C. Lamy, R. Durand, J. Appl. Electrochem. 23 (1993) 197.

[13] T. Frelink, W. Visscher, J.A.R. van Veen, J. Electroanal. Chem. 382 (1995) 65.

[14] P.C. Biswas, Y. Nodasaka, M. Enyo, J. Appl. Electrochem. 26 (1996) 30.

[15] F. Gloagen, J.M. Leger, C. Lamy, J. Appl. Electrochem. 27 (1997) 1052.

[16] F. Montilla, E. Morallón, J.L. Vázquez, J. Alcañiz-Monge, D. Cazorla-Amorós, A. Linares-Solano, Carbon 40 (2002) 2193.

[17] D. Gandini, E. Mahé, P.A. Michaud, W. Haenni, A. Perret, Ch. Comninellis, J. Appl. Electrochem. 30 (2000) 1345.

[18] M. Paunovic, M. Schlesinger, Fundamentals of Electrochemical Deposition, Wiley, New York, 1998.

[19] B. Scharifker, G. Hills, Electrochim. Acta 28 (1983) 879.

[20] F. Gloagen, J.M. Léger, C. Lamy, A. Marmann, U. stimming, R. Vogel, Electrochim. Acta 44 (1999) 1805. 